Research Article

\title{
Pool Boiling of Micro-/Nanoparticles Modified Aluminum Surface
}

\author{
Chin-Ting Yang and Chia-Cheng Yu \\ St. John's University 499, Section 4, Tam King Road Tamsui, New Taipei City 25135, Taiwan \\ Correspondence should be addressed to Chin-Ting Yang; ctyang@mail.sju.edu.tw
}

Received 15 September 2013; Accepted 9 November 2013

Academic Editor: Ching-Song Jwo

Copyright (C) 2013 C.-T. Yang and C.-C. Yu. This is an open access article distributed under the Creative Commons Attribution License, which permits unrestricted use, distribution, and reproduction in any medium, provided the original work is properly cited.

\begin{abstract}
The purpose is to investigate the boiling heat transfer affected by different wettability aluminum surfaces. The hydrophobic and hydrophilic surfaces were modified from regular surfaces by sol-gel method. The water contact angles of sample surfaces are 150, 75 , and 5 degrees. All the samples were tested by a carefully designed thermal system. The experimental results revealed that, at the same wall superheat condition, the hydrophilic surface had higher boiling heat flux and hydrophobic surface possessed the lowest. The boiling bubble generation images suggested that bubble formation rate and shape strongly affected the values of heat flux. The lower contact angle surface generated fewer bubbles at high heat flux state such that liquid could contact with larger part of solid interface and transfer more heat than other kinds of surfaces. For the high contact angle surface, at very high heat flux condition, the bubbles even collapsed into vapor film. Part of heat transferred to liquid was blocked by the film and caused the wall superheat to increase dramatically and finally damaged the sample. This heat flux limitation was called critical heat flux. The hydrophilic surface that possessed higher critical heat flux was also measured in this study.
\end{abstract}

\section{Introduction}

A lot of heat could be transferred to liquid through the heating surface during pool boiling heat transfer. The temperature of fluid remained saturated and the superheat of heating surface changed with the heat flux [1]. The maximum heat flux of boiling curve where wall superheat was going to increase dramatically was called critical heat flux (CHF). And the heating surface wettability is one of the important factors that affect CHF [2]. Also bubbles generated from heating surface were easily observed during pool boiling heat transfer. The number and size of bubbles affect heat flux significantly. Since to enhance the pool boiling heat transfer is an important issue for high power density cooling system, there are many researchers focusing on studying the relationship between $\mathrm{CHF}$ and wettability. But most of them concentrated on the copper surfaces [3]. However, considering the lighter density and easy manufacturing of aluminum material, there are also many cooling systems harnessing those characteristics to solve the heat dissipation problems, for example, heat pipe, vapor chamber, and evaporator heat exchanger.
Jo et al. [4] used E-Beam to deposit platinum thin film as heater on one side of water and the other side modified as sample surface. The sample surfaces included regular water surface whose water contact angle was $54^{\circ}$ and also was called hydrophilic. And the other sample surface was modified by MEMS processes to coat hydrophobic material, Teflon, with patterned structures. The contact angle was $123^{\circ}$ (called as hydrophobic). They concluded that under very low heat flux transfer condition, the hydrophobic surface offered better nucleate boiling heat transfer. Also, a heterogeneous wettability surface provided better nucleate boiling heat transfer than that of the homogeneous ones. Hsu et al. [3] modified the copper surfaces to be with homogeneous or interlaced wettability by nanoparticles self-assembly method. Experimented with home-made setup, they observed the CHF of heating surfaces from high to low were interlaced, iso-hydrophilic, regular, and iso-hydrophobic surfaces. Phan et al. [5] also used nanocoating techniques to modify the regular steel surfaces to form different wettability. The surface contact angles varied from $20^{\circ}$ to $110^{\circ}$. Due to the disagreement of results with classic model, they proposed macro-and micro contact angle 


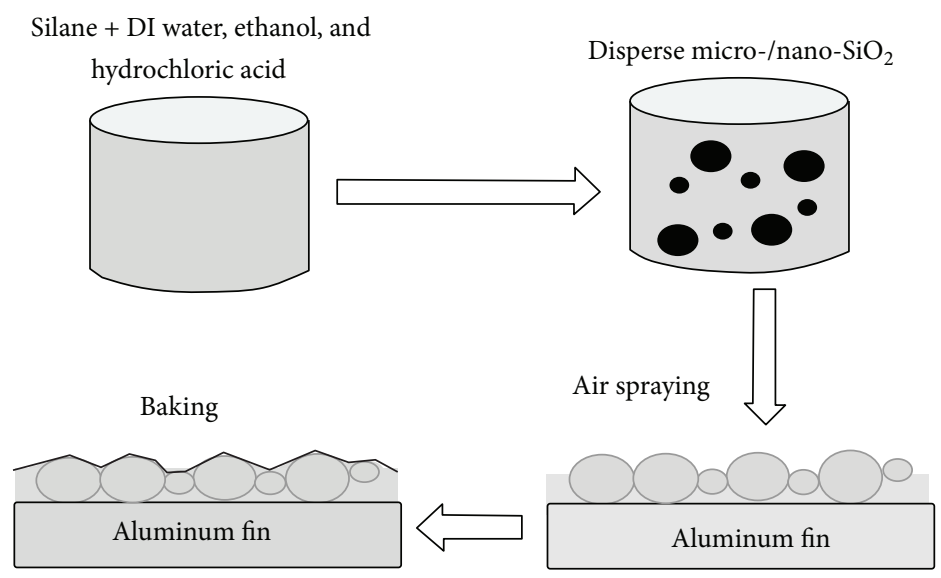

FIGURE 1: Illustration of surface modification processes.

model to explain the observed phenomenon. In this study, regular aluminum surfaces were modified to be hydrophobic or hydrophilic by self-assembly method. In order to improve the uniformity and the adhesion of particles, dipping process was replaced by air spraying. After surfaces modification, the samples were attached to the thermal test system and measured the boiling heat transfer flux against heating surface superheat. The temperature data and bubbles generation or vapor film formation images were taken for discussion.

\section{Materials and Methods}

2.1. Aluminum Surface Modification. The different wettability aluminum surfaces were modified by the self-assembly method. The rough structures were formed on surface with particles of dual sizes of diameters and silane acting as coupler. In the modification processes the dipping was replaced by air spraying in order to form firm structure on surface. The hydrophobic surface of rough structure in micro-/nanoscales was first reported by Barthlott and Neinhuis [6]. But the theory was proposed much earlier. Young [7] stated that when a liquid drops on a flat homogeneous solid surface, the contact angle was decided by the balance of surface tension forces which are between the solid, liquid, and vapor. The relation was expressed as

$$
\cos \theta=\frac{\gamma_{\mathrm{SV}}-\gamma_{\mathrm{SL}}}{\gamma_{\mathrm{LV}}},
$$

where $\theta$ is contact angle in degree; $\gamma_{\mathrm{SV}}$ is surface tension, and the subscripts $S, L$, andV represent solid, liquid, and vapor respectively. If the surface was with roughness rather than plan, Cassie and Baxter [8] modified Young's expression as

$$
\cos \theta_{C}=f_{1} \cos \theta_{1}+f_{2} \cos \theta_{2},
$$

where $\theta_{C}$ is contact angle predicted by Cassie-Baxter model $f_{1}$ and $f_{2}$ are fractions of solid and air inside an interval length of roughness. $\theta_{1}$ is contact angle predicted by Young's model. When a water drop is in air, $\theta_{2}$ is $180^{\circ}$. As predicted by Cassie-Baxter model, different wettability surfaces could be obtained by forming rough-structure on surfaces and controlling the ratio of micro-and nanoparticles. The modification processes were illustrated in Figure 1. The first step was to mix methyltrimethoxysilane (METMS), distilled (DI) water, ethanol, and some Hydrochloric Acid, to form solution, and then uniformly dispersed (by ultrasonic vibrator) micro-/nano silica dioxide particles into the solution. The following procedure was to clean to and airspray the gel-like solution onto the aluminum surface. The final step was to put the sample into oven to bake it with some preset temperature cycles. The water contact angles of modified surfaces were measured by contact angle goniometer (model 100SL, Sindatek, Taiwan). With the analysis of the provided software, the measurement accuracy could be within 1 degree. The contact angles showed in this paper were the average of nine measurements at different locations for each sample.

2.2. Thermal System. The heating system used to measure the heat transfer flux of aluminum surfaces is shown schematically in Figure 2. There are three-nominal power of $200 \mathrm{~W}$ heaters inside the heating copper cylinder. The diameter of heating cylinder is $60 \mathrm{~mm}$. The AC line is connected to voltage regulator and the output current flows through power meter and finally into heaters. Such that power supplied from power control unit could be controlled by regulating the voltage and read from the power meter panel. The heating surface is on the top of neck cylinder which is the same block of heating cylinder. The diameter of neck cylinder is $19 \mathrm{~mm}$, but the length is only $10 \mathrm{~mm}$. And two K-type thermocouples (0.079 mm of wire diameter, TPK-0.1-40G, TECPEL, Taiwan) were placed inside this cylinder. The distance between the two thermocouples was $4 \mathrm{~mm}$. The temperature reading collected by the data logger (DTM319, TECPEL, Taiwan) was transferred to PC for analysis. According to the Fourier law and under one-dimensional assumption, $q$ the heat flux to heating surface could be calculated as

$$
q=k \frac{T_{1}-T_{2}}{\Delta z}
$$

where $k=402 \mathrm{~W} / \mathrm{m}^{\circ} \mathrm{C}$ is thermal conductivity of copper, $T_{1}$ and $T_{2}$ are the temperatures measured by the two thermocouples, and $\Delta z$ is the distance between two thermocouples. 


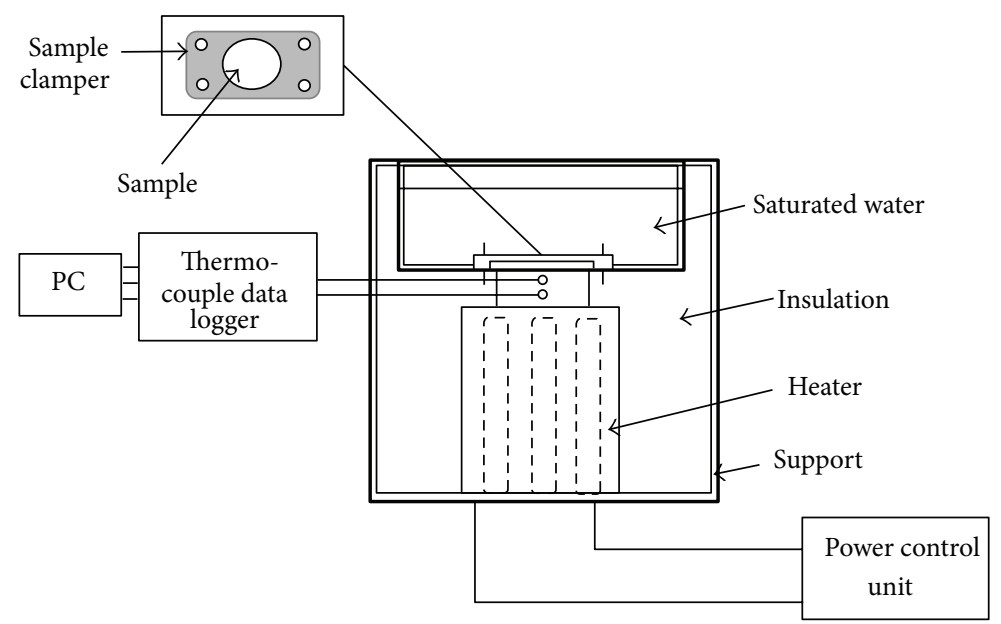

FIGURE 2: Schematic picture of heating system.

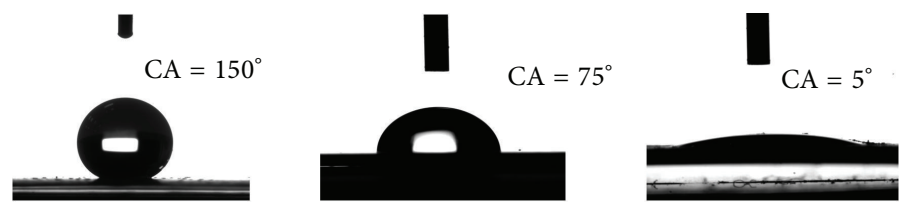

FIGURE 3: Aluminum surfaces of different wettability.

The top part of cylinder neck was brazed to a water container and the heating surface (top surface of neck cylinder) had the same level with bottom plate of container. Two other thermocouples were used (not shown in figure) to monitor the temperatures of water and interface between heating surface and water which both were kept at the saturated state during experiment. In order to minimize the thermal contact resistance, a copper cover plate with a hole of $19 \mathrm{~mm}$ diameter was used to fix the aluminum sample. The cover plate was fastened to the bottom plate by four screws. Also, thermal grease was applied between heating surface and sample. The temperature of sample surface was extrapolated by $T_{1}$ and $T_{2}$ with actual distances from surface. Insulating material was fully filled between water container and support box to reduce heat transfer to the surrounding area. One extra thermometer was attached to the surface of box to monitor the temperature change. By doing the energy balance analysis, the heat loss through insulation was proportional to heat transfer flux. The maximum heat loss was $3.1 \%$ of the power supplied.

\section{Discussion and Result}

3.1. Hydrophobic and Hydrophilic Samples. As predicted by Cassie and Baxter's model, formation of roughness structure on aluminum surface really did improve the water contact angle which meant to be more hydrophobic. In our modifications, METMS silane solution with addition of $9.6 \mathrm{wt} \%$ of silica oxide particles formed the best hydrophobic surface. The silica oxide particles included $80 \%$ of nanoparticles $(99.5 \%$ diameter between 10 and $20 \mathrm{~nm}$, Sigma-Aldrich, USA) and the rest of microparticles ( $80 \%$ diameter between 1 to $5 \mu \mathrm{m}$,
Sigma-Aldrich, USA). The contact angle changed from $75^{\circ}$ to $150^{\circ}$, as shown in the left part of Figure 3. The SEM images shown in Figure 4 could reveal the microstructure dispersed on the modified aluminum surface and the higher resolution image also could show the nanostructure around the microparticles which was very similar to the lotus leaf structure [5]. The contact angle of regular plain aluminum surface is $75^{\circ}$ which was also reported in many papers. The hydrophilic surface modification procedures were the same as those of the hydrophobic one, except one more high temperature baking. The bond attraction of METMS silane to water molecule is higher than to silica particles. The water drop laid flatly on the surface. The water contact angle was only $5^{\circ}$. Since the particles were deposited to the surface by air spraying, the adhesive force was stronger than the dipping method. Also the surface wettability could be kept longer for at least more than 1 year.

3.2. Boiling Heat Flux of Copper Surface. The heating cylinder was made of copper and the heating surface also can be as one sample surface. Without attaching any sample to the heating surface, the boiling heat transfer flux of copper surface could be tested. Water with temperature of near $100^{\circ} \mathrm{C}$ was added to the container. Power consumed by heaters was controlled by voltage regulator. Two temperatures inside the cylinder neck and two inside the water container were recorded by PC. The temperature curves were shown in Figure 5. After a period of time, the two temperatures, top and bottom liquid temperatures, inside the water container were approaching $100^{\circ} \mathrm{C}$. And the other two temperatures were approaching two steady values which were $T_{1}$ and $T_{2}$ in (3). The one far 

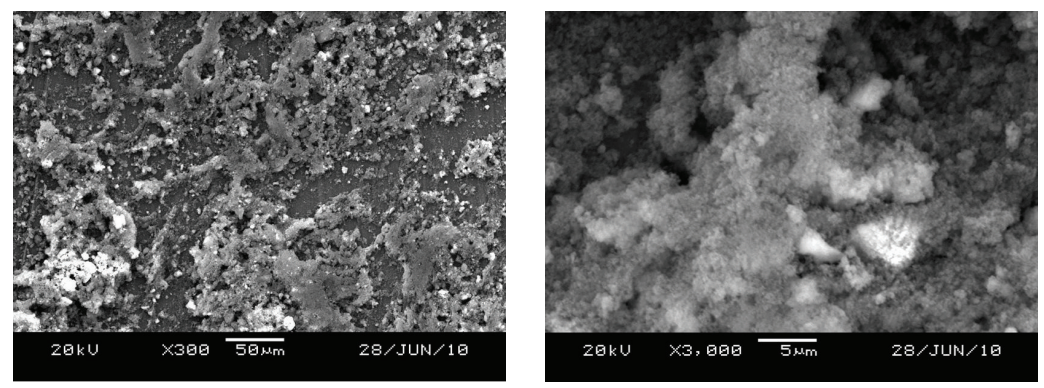

Figure 4: Low and high resolution SEM images of structure on surface $\left(\mathrm{CA}=150^{\circ}\right)$.

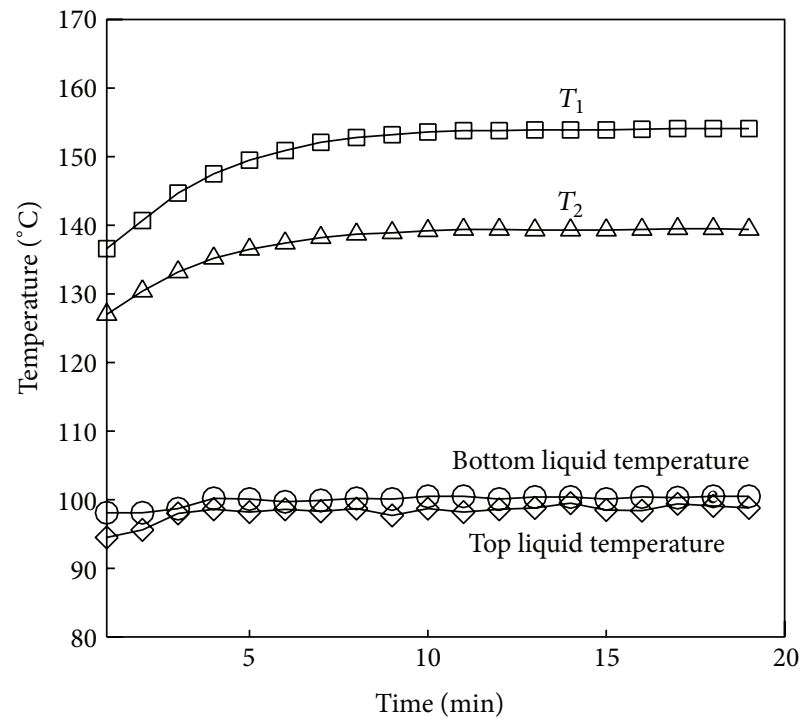

FIGURE 5: Temperature curves for one heat flux experiment.

away heating surface was called $T_{1}$, such that the heat flux transferred to heating surface could be calculated by (3). However, the calculated heat flux was smaller than that of direct reading from power meter, because part of the heat still could dissipate to the surrounding through the insulation material. But the calculated heat flux must be very close to the heat flux through heating surface for the short length design of cylinder neck. For all test cases, the maximum heat flux dissipated to surrounding was $3.1 \%$. The heat flux in this study was all calculated from (3). The heating surface temperatures employed similar equation to extrapolate. At the interface of heating surface and water, the temperature was kept the same as liquid. This was the reason why it was not easy to measure the wall temperature directly. However, assuming the heat flux was conservative in short length cylinder, it was much easier to extrapolate the wall temperature and calculate the wall superheat. If any test sample plate was attached to the heating surface, the thermal conductivity in (3) should be modified as composite material. Figure 6 was the comparison of copper surface boiling heat flux curve with Hsu et al. [3]. The trend was very similar. The contact angle of our regular copper surface was $85^{\circ}$, but it was $73^{\circ}$ for Chen's sample. For our system, if the heat flux was too low, the voltage regulator

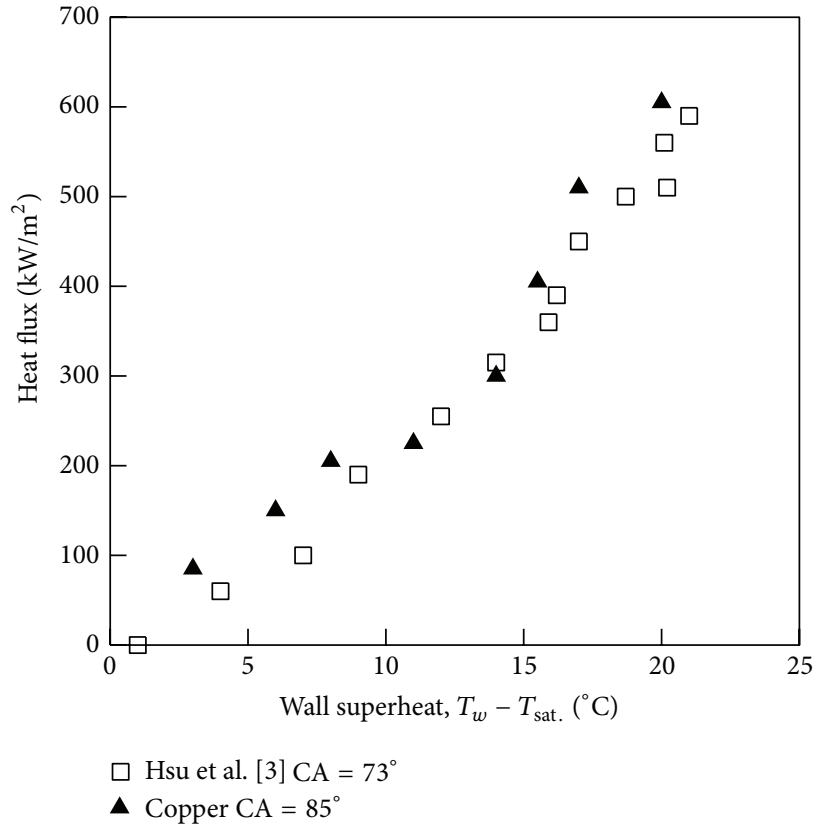

FIGURE 6: Comparison of copper surface boiling heat flux curve with Hsu et al. [3].

was hard to control. The two temperatures $T_{1}$ and $T_{2}$ were close and hard to determine. So there was a lower limitation to measure the heat flux.

3.3. Boiling Curves of Aluminum Surfaces. The aluminum surface's heat flux against wall superheat plots were shown in Figure 7. The opened circle symbol line represented boiling curve of hydrophobic surface. In comparison with copper surface (Figure 6), if both are at the same heat flux the wall superheats of aluminum surfaces are much higher. The reason was that the thermal conductivity of aluminum was smaller than that of copper. For aluminum surface, according to (3), the smaller thermal conductivity needs higher temperature gradient to keep the same heat flux. From the plot, CHF of hydrophobic surface was $603 \mathrm{~kW} / \mathrm{m}^{2}$ when the surface superheat was $163^{\circ} \mathrm{C}$. The solid square symbol line was the heat flux curve for regular aluminum surface. Being close to the hydrophobic curve, when the wall superheat reached $186^{\circ} \mathrm{C}$ the boiling heat flux rise was 


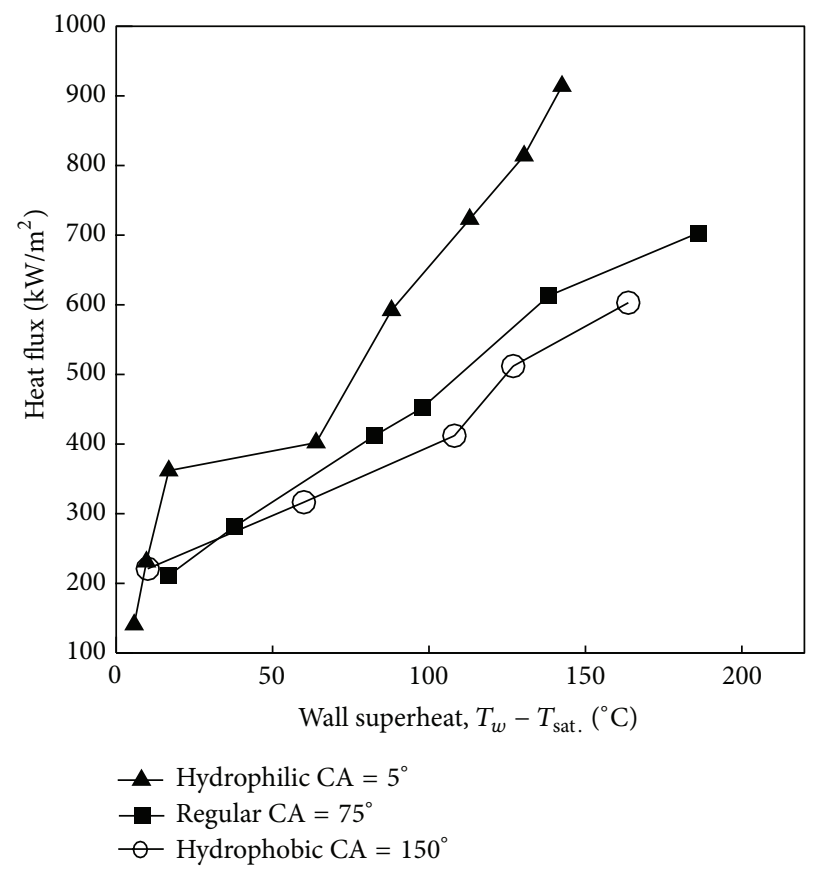

FIGURE 7: Wall superheat and heat flux plots for different wettability surfaces.
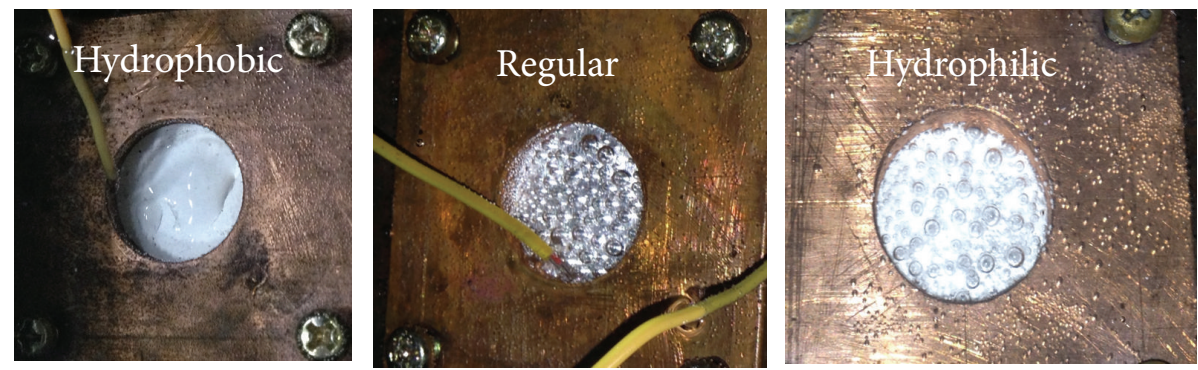

FIGURE 8: Film or bubbles formed during boiling heat transfer for different wettability surfaces.

as high as $703 \mathrm{~kW} / \mathrm{m}^{2}$. Larger than this wall superheat, the boiling condition turned into being unstable gradually. If only the heat flux slightly increased, the wall superheat then would have been increasing very quickly. On the surface, part of the bubbles collapsed into vapor film and blocked the heat transfer into the liquid. Then, most of energy would heat up the aluminum sample and cause the wall superheat increase out of control. Finally, the temperature was over the limitation of material and damaged the sample. The solid delta symbol line represented the hydrophilic surface's boiling curve. At lower wall superheat, the boiling curve was steeper than others. There were few bubbles generated during this stage. If the wall superheats were between 17 and $64^{\circ} \mathrm{C}$, the wall superheats increased dramatically with only a little increasing of heat flux. Higher bubbles generated rate was observed in this period of time. The CHF of the hydrophilic surface could reach as high as $914 \mathrm{~kW} / \mathrm{m}^{2}$ and the corresponding wall superheat was $143^{\circ} \mathrm{C}$. Figure 8 showed the pictures which were taken at the boiling heat flux around $600 \mathrm{~kW} / \mathrm{m}^{2}$. When the surface was hydrophilic, bubbles were not as many as others. The saturated liquid still could contact with major part of heating area directly and transfer energy. The wall superheat was the lowest at this heat flux. For the regular aluminum surface, the contact angle was $75^{\circ}$ and bubbles were generated easily. Most of the heating area was covered with small size bubbles. The bubbles prevented heat dissipation from surface into liquid and then increase the wall superheat. Compare to the hydrophilic surface, the wall superheat increased about $50^{\circ} \mathrm{C}$ at the same heat flux. When the surface was hydrophobic, very different phenomena were observed. The modified micro-/nanostructure trapped a lot of air to form hydrophobic characteristic. This kind of structure generated bubbles easily during boiling heat transfer. For higher heat flux case, even some bubbles collapsed into film and increased the wall superheat very much.

\section{Summary}

Concluding the discussion, the sol-gel method successfully modified the regular aluminum surfaces to be hydrophobic 
or hydrophilic. In this study the contact angles were $150^{\circ}$ and $5^{\circ}$, respectively. The bubble number and size were smaller for the hydrophilic surface which let the saturated liquid contact with heating surface easily. This was a benefit to boiling heat transfer. Such that the boiling heat flux and CHF depended on the wettability of the surfaces. For regular aluminum the $\mathrm{CHF}$ was $703 \mathrm{~kW} / \mathrm{m}^{2}$, but for the hydrophilic surface the CHF could be as high as $914 \mathrm{~kW} / \mathrm{m}^{2}$ and only was $603 \mathrm{~kW} / \mathrm{m}^{2}$ of the hydrophobic surface.

\section{Acknowledgment}

The authors would like to acknowledge the financial support provided by the National Science Council of Taiwan, under Contract no. NSC 101-2221-E-129-009.

\section{References}

[1] S. Nukiyama, "The maximum and minimum values of heat $\mathrm{Q}$ transmitted from metal to boiling water under atmospheric pressure," Journal of the Japan Society of Mechanical Engineers, vol. 37, pp. 367-374, 1934.

[2] M. Maracy and R. H. S. Winterton, "Hysteresis and contact angle effects in transition pool boiling of water," International Journal of Heat and Mass Transfer, vol. 31, no. 7, pp. 1443-1449, 1988.

[3] C. C. Hsu, T. W. Su, and P. H. Chen, "Pool boiling of nanoparticle-modified surface with interlaced wettability," Nanoscale Research Letters, vol. 7, pp. 259-266, 2012.

[4] H. Jo, H. S. Ahn, S. Kang, and M. H. Kim, "A study of nucleate boiling heat transfer on hydrophilic, hydrophobic and heterogeneous wetting surfaces," International Journal of Heat and Mass Transfer, vol. 54, no. 25-26, pp. 5643-5652, 2011.

[5] H. T. Phan, N. Caney, P. Marty, S. Colasson, and J. Gavillet, "How does surface wettability influence nucleate boiling?" Comptes Rendus Mecanique, vol. 337, no. 5, pp. 251-259, 2009.

[6] W. Barthlott and C. Neinhuis, "Purity of the sacred lotus, or escape from contamination in biological surfaces," Planta, vol. 202, no. 1, pp. 1-8, 1997.

[7] T. Young, "An essay on the cohesion of fluids," Philosophical Transactions of the Royal Society of London, vol. 95, pp. 65-87, 1805.

[8] A. B. D. Cassie and S. Baxter, "Wettability of porous surfaces," Transactions of the Faraday Society, vol. 40, pp. 546-551, 1944. 

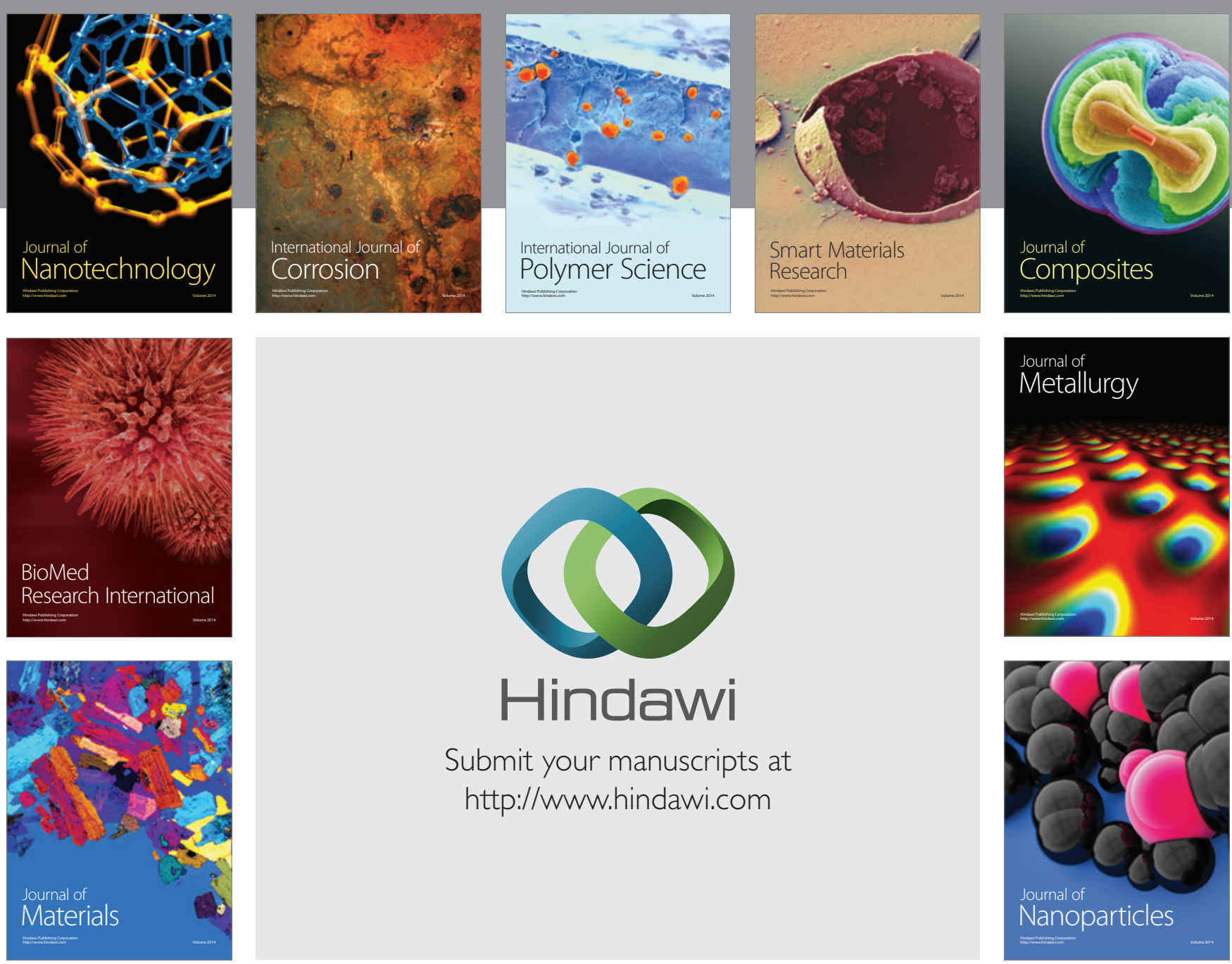

Submit your manuscripts at http://www.hindawi.com
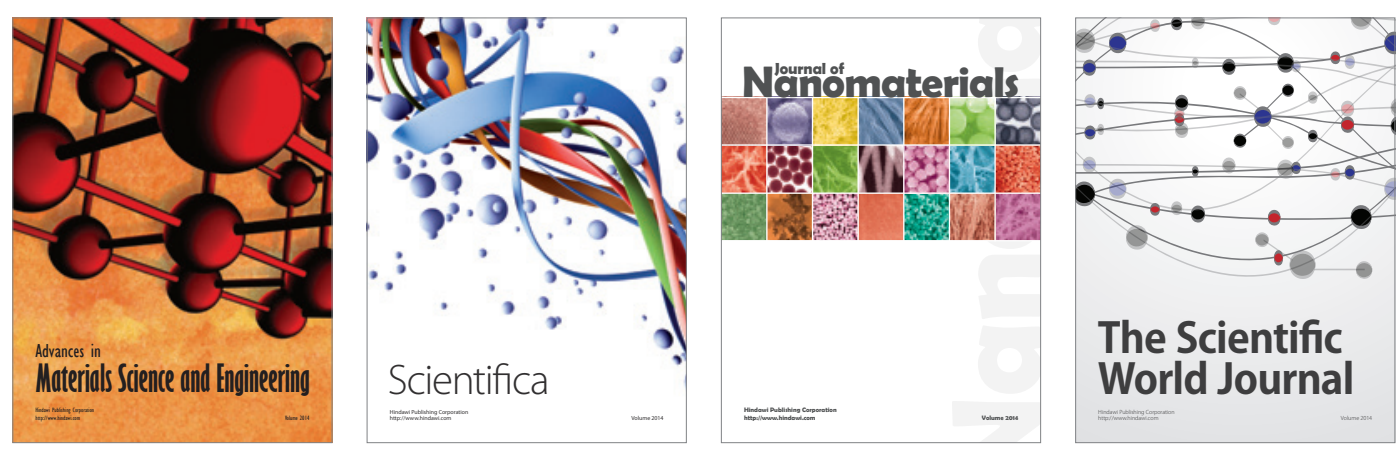

\section{The Scientific World Journal}
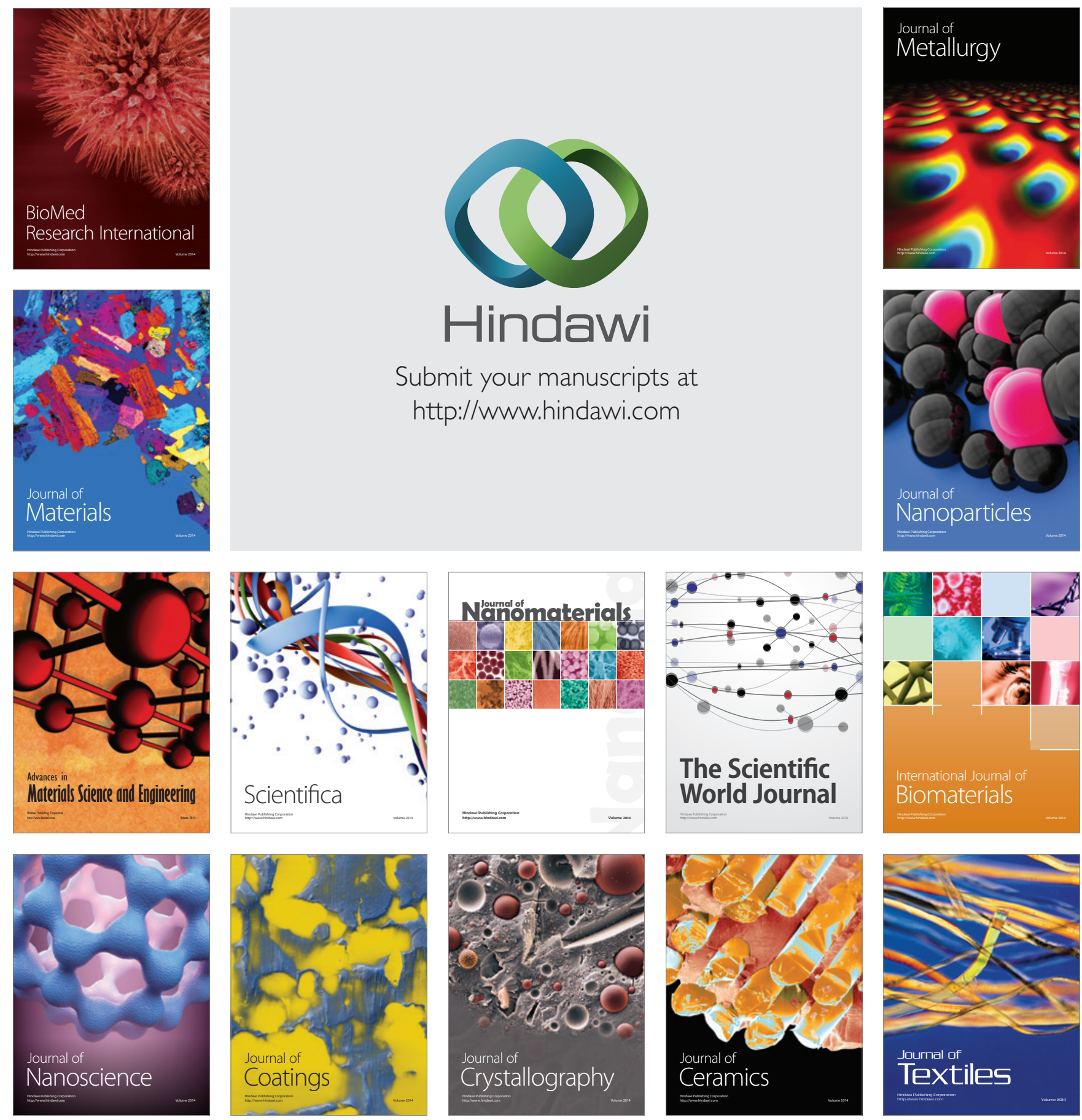